\title{
Relationship between Oxidative Stress, Serum Zinc Level and Systemic Arterial Blood Pressure in Smokers and Non-smokers
}

\author{
Zarchi Theint Theint Hlaing*, Myat Su Bo, Mya Mya Thwin
}

\section{Zarchi Theint Theint Hlaing*, Myat Su Bo, Mya Mya Thwin}

Department of Physiology, University of Medicine-Magway, Natmauk Road, Magway, Township, Magway Regional Division, MYANMAR.

\section{Correspondence}

\section{Dr. Zarchi Theint Theint Hlaing} Department of Physiology, University of Medicine-Magway, Natmauk Road, Magway, Township, Magway Regional Division, MYANMAR.

Phone: +95943009631

Email: zarchi.tth@gmail.com

\section{History}

- Submission Date: 18-06-2019;

- Review completed: 12-07-2019;

- Accepted Date: 25-09-2019.

DOI : 10.5530/ijcep.2019.6.3.27

\section{Copyright}

(c) 2019 Phcog.Net. This is an openaccess article distributed under the terms of the Creative Commons Attribution 4.0 International license.

\begin{abstract}
Background and Aim: Either active or passive smoking causes damage to the heart and blood vessels. The aim of this study is to investigate the relationship between oxidative stress, serum zinc level and systemic arterial blood pressure in smokers and non-smokers. Methods: A cross sectional comparative study was done. Apparently healthy subjects of age 18-45 years including 40 smokers and 40 non-smokers residing in Magway Township, Myanmar were recruited. Serum zinc level was measured by atomic absorption spectrophotometry method. Serum malondialdehyde level was used as oxidative stress marker and measured by spectrophotometry. Systemic arterial blood pressure was measured by indirect method using mercury sphygmomanometer. Results: Mean serum zinc level of smokers $(51.25 \pm 7.5 \mu \mathrm{g} / \mathrm{dL})$ was significantly lower than that of non-smokers $(92.91 \pm 27.46$ $\mu \mathrm{g} / \mathrm{dL})(P<0.001)$. Mean serum malondialdehyde level of smokers $(0.78 \pm 0.14 \mu \mathrm{mol} / \mathrm{L})$ was significantly higher than that of non-smokers $(0.24 \pm 0.09 \mu \mathrm{mol} / \mathrm{L})(P<0.001)$. Mean Systolic Blood Pressure (SBP) of non-smokers was $120.95 \pm 5.02 \mathrm{mmHg}$ and that of smokers was $126.55 \pm 6.14 \mathrm{mmHg}(P<0.05)$. There was significant negative correlation between serum malondialdehyde level and serum zinc level $(r=-0.75, P<0.001, n=80)$. There was also significant negative correlation between serum zinc level and SBP $(r=-0.477, p<0.001$, $n=80$ ). There was positive correlation between serum malondialdehyde level and SBP $(r=0.487, p<0.001, n=80)$. Conclusion: It could be concluded that smoking increases oxidative stress and decreases serum zinc level and these two changes might contribute to increase in blood pressure in smokers.

Key words: Serum zinc level, Serum malondialdehyde level, Smoking, Systolic blood pressure, Oxidative stress.
\end{abstract}

\section{INTRODUCTION}

Smoking is one of the lifestyle factors that distress the health of human and have been killing millions of human beings for many centuries. ${ }^{[1]}$ It is one of the major risk factors for the development of atherosclerosis, coronary heart disease, acute myocardial infarction and sudden cardiac death. ${ }^{[2]}$

Cigarette smoke contains over 4700 different chemicals. Many of these are oxidants and pro-oxidants that can produce free radicals and enhance the oxidative stress. ${ }^{[3]}$ Malondialdehyde (MDA) is generated from Reactive Oxygen Species (ROS) and one of the most frequently used indicators of oxidative stress markers. ${ }^{[4]}$ Oxygen free radicals can directly initiate the process of lipid peroxidation that contributes to cardiovascular diseases. ${ }^{[5]}$

Cigarette smoke contains reactive peroxyl radicals and acetaldehyde which can increase lipid peroxidation. It can also be connected with the production of free radicals by polymorphonuclear leucocytes. Free oxygen radicals also caused tissues and microvascular damage. ${ }^{[6]}$ Oxidative stress promotes vascular smooth muscle cell proliferation and hypertrophy

Cite this article: Hlaing ZTT, Bo MS, Thwin MM. Relationship between Oxidative Stress, Serum Zinc Level and Systemic Arterial Blood Pressure in Smokers and Non-smokers. Int J Clin Exp Physiol. 2019;6(3):100-3. 
Cardiovascular disease is extensively recognized as one of the leading causes of death globally. Smoking is one of the major risk factors for cardiovascular diseases. It is required to explore the link between smoking and cardiovascular diseases. Therefore, this study was designated to find out the incidence of zinc deficiency as well as the relationship between oxidative stress, serum zinc level and systemic arterial blood pressure in smokers.

\section{MATERIALS AND METHODS}

\section{Selection of Participants}

Apparently healthy male subjects aged between 18-35 years residing in Magway Township, Myanmar were selected. From these subjects, 40 smokers and 40 non-smokers were selected by simple random sampling method. The procedure was explained and written informed consent was obtained. Detailed smoking characteristics including age at which the subject started smoking, duration of smoking and the number of cigarettes/cheroots smoked per day was recorded.

\section{Data Collection and Blood Sample Analysis}

Systemic brachial arterial blood pressure was measured in lying position by indirect method using mercury sphygmomanometer. The level of pressure at which Korotkoff sound first heard (Stage I) was taken as Systolic Blood Pressure (SBP) and the level of pressure at which Korotkoff sound disappears (Stage V) as Diastolic Blood Pressure (DBP). The average of three measurements taken one minute interval was used.

Ten $\mathrm{ml}$ of fasting venous blood was withdrawn from antecubital vein under aseptic condition by using a disposable syringe and needle for each subject. After collection of blood sample, samples were centrifuged $1500 \mathrm{rpm}$ for $10 \mathrm{~min}$ to obtain serum. Serum MDA was used as indicator of oxidative stress. Serum MDA level was determined by spectrophotometry at Common Research Laboratory, University of Medicine, Magway, Myanmar. For determination of zinc level, serums were collected in two separate sample tubes and stored at $\left(-20^{\circ} \mathrm{C}\right)$ in Common Research Laboratory, University of Medicine, Magway, Myanmar. Serum zinc level was determined by atomic absorption spectrophotometry at Common Research Laboratory, University of Medicine-2, Yangon, Myanmar.

\section{Statistical Analysis of Data}

Data were analyzed by using SPSS software for Window (version 23, SPSS Inc., Chicago, IL, USA). Data was described by mean \pm SD. Independent student's $t$-test was used to compare the continuous variables. Correlation studies were computed by Pearson's correlation. The significant level of $p<0.05$ was accepted.

\section{RESULTS}

Baseline characteristics of the subjects were shown in Table 1. Mean serum zinc level of smokers $(51.25 \pm 7.5 \mu \mathrm{g} / \mathrm{dL})$ was significantly lower than that of non-smokers $(92.91 \pm 27.46 \mu \mathrm{g} / \mathrm{dL})(P<0.001)$ [Figure 1]. Mean serum MDA level of smokers $(0.78 \pm 0.14 \mu \mathrm{mol} / \mathrm{L})$ was significantly higher than that of non-smokers $(0.24 \pm 0.09 \mu \mathrm{mol} / \mathrm{L})(P<0.001)$ [Figure 2]. Mean Systolic Blood Pressure (SBP) of non-smokers was $120.95 \pm 5.02$ $\mathrm{mmHg}$ and that of smokers was $126.55 \pm 6.14 \mathrm{mmHg}(P<0.05)$ [Figure 3]. There was no significant difference in mean Diastolic Blood Pressure (DBP) between smokers $(78.9 \pm 6.7 \mathrm{mmHg})$ and non-smokers $(77.15 \pm$ $5.4 \mathrm{mmHg}$ ). Mean Arterial Pressure (MAP) of non-smokers was $90.95 \pm$ $4.97 \mathrm{mmHg}$ and that of smokers was $93.27 \pm 5.68 \mathrm{mmHg}(P>0.05)$.

There was significant negative correlation between serum MDA level and serum zinc level $(r=-0.75, P<0.001, n=80)$ [Figure 4]. There was also significant negative correlation between serum zinc level and SBP
Table 1: Baseline characteristics of the subjects.

\begin{tabular}{ccc} 
Parameters & $\begin{array}{c}\text { Smokers } \\
(\mathrm{n}=40) \\
{[\text { Mean } \pm \text { SD }]}\end{array}$ & $\begin{array}{c}\text { Non-smokers } \\
(\mathrm{n}=40) \\
{[\text { Mean } \pm \text { SD] }}\end{array}$ \\
\hline Age (years) & $26.00 \pm 7.20$ & $21.20 \pm 4.69$ \\
Height $(\mathrm{m})$ & $1.67 \pm 0.04$ & $1.68 \pm 0.05$ \\
Body Weight $(\mathrm{kg})$ & $55.58 \pm 10.04$ & $55.55 \pm 7.64$ \\
BMI $\left(\mathrm{kg} / \mathrm{m}^{2}\right)$ & $19.82 \pm 3.54$ & $19.73 \pm 2.42$
\end{tabular}

BMI = Body Mass Index; $\mathrm{n}=$ number of subjects.

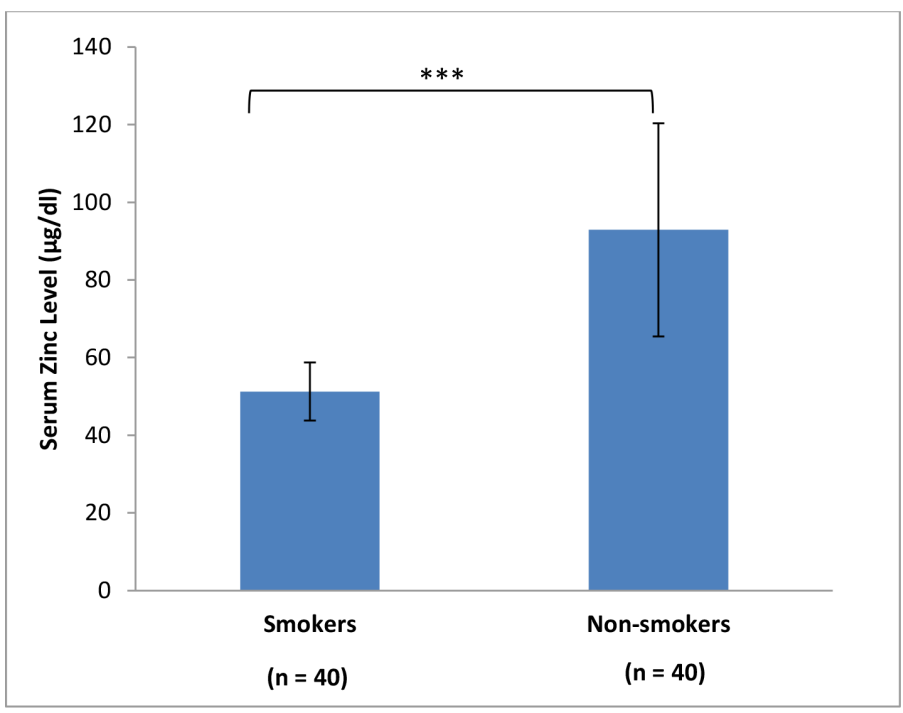

Figure 1: Comparison of serum zinc level in smokers and non-smokers. *** indicates $p<0.001$

$n=$ total number of subjects

Comparison was done by Independent student's $t$-test.

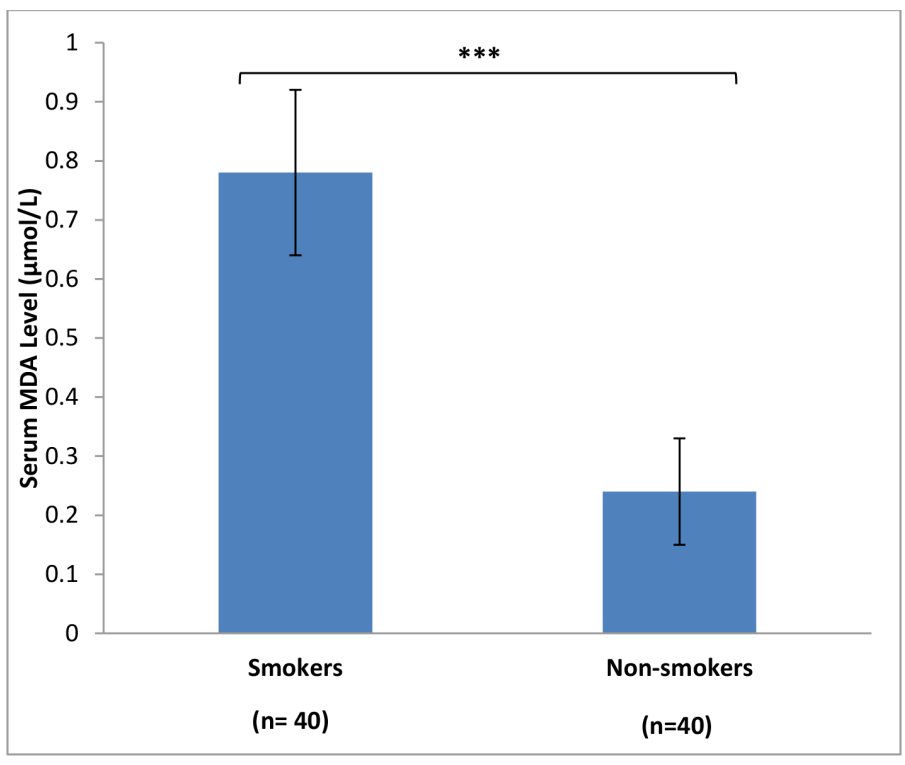

Figure 2: Comparison of serum MDA level in smokers and non-smokers. MDA = Malondialdehyde

*** indicates $p<0.001$

$n=$ total number of subjects

Comparison was done by Independent student's $t$-test. 


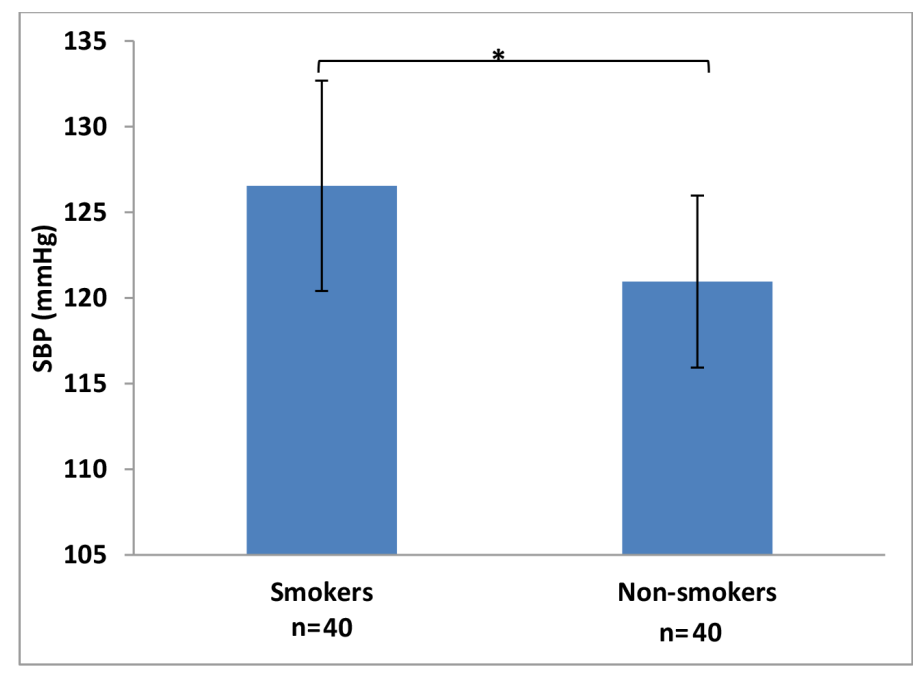

Figure 3: Comparison of SBP in smokers and non-smokers.

$\mathrm{SBP}=$ Systolic blood pressure

*indicates $p<0.05$

$n=$ total number of subjects

Comparison was done by Independent student's $t$-test.

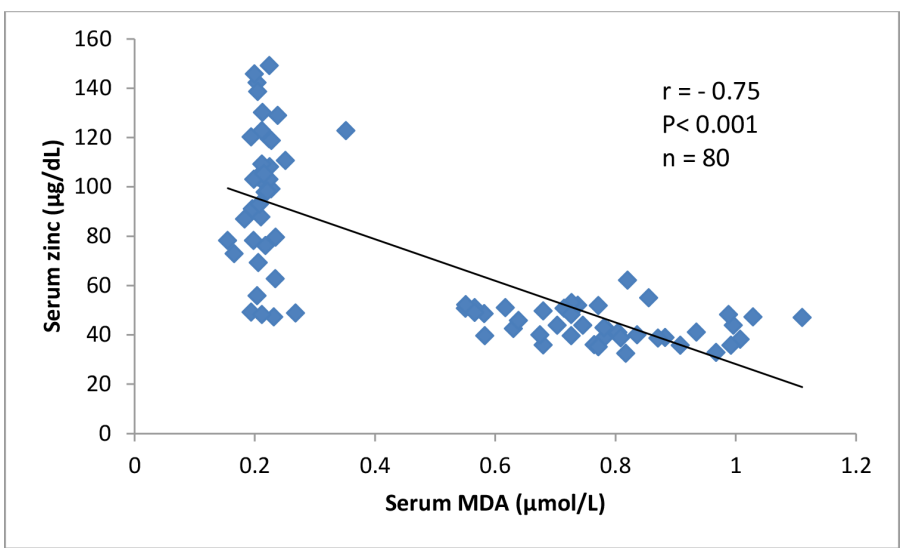

Figure 4: Correlation between serum MDA level and serum zinc level. $r=$ Pearson's correlation coefficient

$n=$ total number of subjects

$\mathrm{MDA}=$ Malondialdehyde.

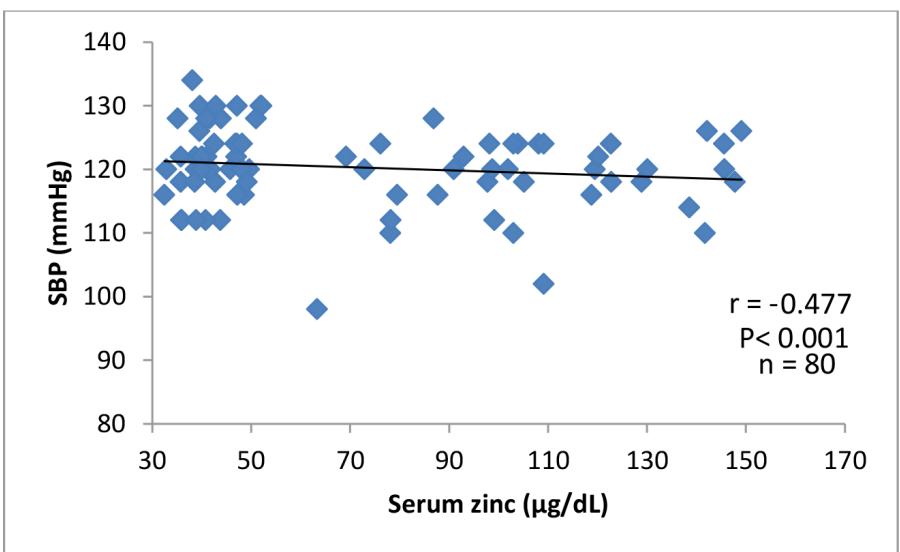

Figure 5: Correlation between serum zinc level and SBP.

$r=$ Pearson's correlation coefficient

$n=$ total number of subjects

$\mathrm{SBP}=$ Systolic blood pressure.

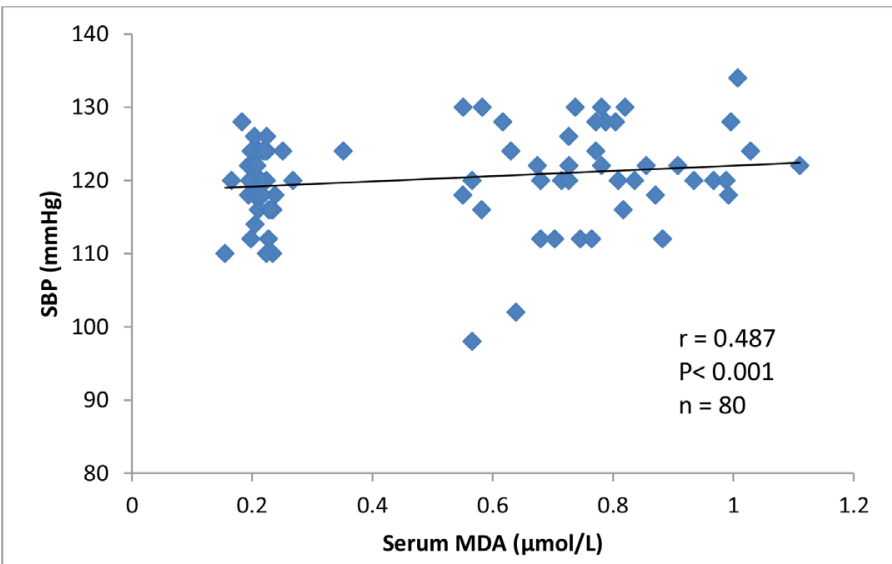

Figure 6: Correlation between serum MDA level and SBP. $r=$ Pearson's correlation coefficient

$n=$ total number of subjects

$\mathrm{SBP}=$ Systolic blood pressure

MDA = Malondialdehyde.

$(r=-0.477, p<0.001, n=80)$ [Figure 5]. There was positive correlation between serum MDA level and SBP $(r=0.487, p<0.001, n=80)$ [Figure 6].

\section{DISCUSSION}

Zinc involves in several metabolic pathways as a cofactor for more than 300 enzymes. Zinc is an essential trace element and vital for many systems in the body ${ }^{[12]}$ Zinc has antioxidant and anti-inflammatory properties. It participates in various enzyme reactions directly related to the regulation of blood pressure and indirectly related to generation of oxidative metabolic energy and alterations in blood lipid levels. ${ }^{[13]}$ The normal serum zinc concentration is $50-120 \mu \mathrm{g} / \mathrm{dL}(0.5-1.2 \mathrm{mg} / \mathrm{L}) .{ }^{[14]}$ Zinc deficiency can cause endothelial activation that favors all stages of atherogenesis. ${ }^{[15]}$ In the present study, serum zinc levels of the smokers were significantly lower than that of non-smokers $(P<0.001)$. This finding agrees with the findings of Khalid and Numair, 2006; Anetor et al. 2008 and Azzawy and Qaicy, 2011. ${ }^{[16-18]}$

Effects of amount of smoking on serum zinc concentration were also assessed in the present study by dividing into two groups. Group 1 contained the subjects who take $\leq 5$ cigarettes per day and group 2 contained the subjects who take $>5$ cigarettes per day. There were 21 subjects in the former group and 19 subjects in the latter group. Serum zinc concentration of the former group was $55.81 \pm 7.16 \mu \mathrm{g} / \mathrm{dL}$ and that of the latter group was $46.22 \pm 3.86 \mu \mathrm{g} / \mathrm{dL}(P<0.05)$. Effects of duration of smoking on serum zinc level were also assessed in the present study by dividing the two groups ( $<5$ year and $\geq 5$ year). There were 23 subjects in the former group and 17 subjects in the latter. Average serum zinc level in the former group was $54.25 \pm 8.26 \mu \mathrm{g} / \mathrm{dL}$ and that of the latter group was $47.95 \pm 4.99 \mu \mathrm{g} / \mathrm{dL}(P<0.05)$. This finding supposed the finding of Anetor et al. 2008 who found that the negative correlation between the duration of smoking and serum zinc level. ${ }^{[17]}$

In the present study, mean serum malondialdehyde level of the smokers $(0.78 \pm 0.14 \mu \mathrm{mol} / \mathrm{L})$ was significantly higher than that of non-smokers $(0.24 \pm 0.09 \mu \mathrm{mol} / \mathrm{L})(P<0.001)$. It was consistent with the studies of Block et al. 2002; Rumley et al. 2004; Bloomer, 2007; Timimi 2010 and Waseem et al. 2012..$^{[4,5,19-21]}$ In the present study, systolic blood pressure of the smokers $(126.55 \pm 6.14 \mathrm{mmHg})$ was significantly higher than that of non-smokers $(120.95 \pm 5.02 \mathrm{mmHg})(P<0.05)$. However, there were no significant differences between DBP and MAP of the two groups. It was consistent with the study of Primatesta et al. 2001 and Mahmud and Feely, 2003. ${ }^{[22,23]}$ 
In the present study, there were significant negative correlation between serum malondialdehyde level and serum zinc level $(r=-0.75, P<0.001$, $n=80)$ as well as serum zinc level and SBP $(r=-0.477, p<0.001, n=80)$. It was consistent with the study of Bergomi et al. 1997 who reported that there was inverse correlation between blood pressures and serum zinc. ${ }^{[24]}$ There was positive correlation between serum malondialdehyde level and systolic blood pressure $(r=0.487, p<0.001, n=80)$. It was consistent with the study of Ahmad et al. 2013..$^{[7]}$

There is a balance between antioxidants and pro-oxidants (free radicals and other reactive species) under normal condition. If there is an increased level of pro-oxidants leading to potential damage known as oxidative stress. This imbalance can be the effect of depletion of endogenous antioxidants and/or increased formation of free radicals and other reactive species. ${ }^{[19]}$

It was found that MDA level showed positive correlation with systemic arterial blood pressure. Thus it showed that oxidative stress is associated with hypertension and there is positive correlation between oxidative stress and level of blood pressure. Oxidative stress promotes vascular smooth muscle cell proliferation, hypertrophy and collagen deposition which leads to thickening of vascular media, narrowing of vascular lumen and aggravate vascular damage. ${ }^{[7]}$

\section{Limitations of the Study}

The present study was a cross-sectional comparative study design and it could just describe the relationship between smoking, serum zinc level, oxidative stress marker and systemic arterial blood pressure. To assess the cause-effect relationship of smoking, serum zinc level and cardiovascular risks, more study designs should be carried out among the large populations.

\section{CONCLUSION}

This study indicated that smokers had higher oxidative stress maker (MDA), lower serum zinc level and increased systolic blood pressure than non-smokers. It supported that smoking increased free radical production, oxidative stress and increased lipid peroxidation. The excess level of oxidant and pro-oxidant could affect the antioxidants level including serum zinc level and that could also affect the blood pressure.

\section{ACKNOWLEDGEMENT}

Nil.

\section{CONFLICT OF INTEREST}

There are no conflict of interest.

\section{Ethical Clearance}

This research was done after receiving the permission from the academic board of postgraduate studies, University of Medicine, Magway, Myanmar.

\section{ABBREVIATIONS}

SBP: Systolic Blood Pressure; DBP: Diastolic Blood Pressure; MDA: Malondialdehyde; ROS: Reactive Oxygen Species; MAP: Mean Arterial Pressure.

\section{REFERENCES}

1. Parrott AC. "Does cigarette smoking cause stress?" American Psychologist. $1999 ; 54(10): 817-20$.
2. Jagtap VR. Study of lipid peroxide, antioxidants and trace elements in acute myocardial infarction. International Journal of Institutional Pharmacy and Life Sciences. 2012;2(2):163-8.

3. Padmavathi P, Reddy VD, Varadacharyulu N. Influence of chronic cigarette smoking on serum biochemical profile in male human volunteers. Journal of Health Science. 2009;55(2):265-70.

4. Rumley AG, Woodward M, Rumley J, Lowe GDO. Plasma lipid peroxides: Relationships to cardiovascular risk factors and prevalent cardiovascular disease. QJ Med Oxford Journals. 2004;97(12):809-16.

5. Timimi DJ, Phil M, Haji MR, Mohammad BY. Zinc status among smokers and non-smokers: Relation to oxidative stress. Duhok Medicine Journal. 2010;4(1):67-73.

6. Nielsen F, Mikkelsen BB, Nielsen JB, Andesen HR, Grandjean P. Plasma malondialdehyde as biomarker for oxidative stress: Reference interval and effects of life-style factors. Clinical Chemistry. 1997;43(4):1209-14.

7. Ahmad A, Hossain MM, Singhal U, Najamul I. Comparative study of marker of oxidative stress among normotensive, prehypertensive and hypertensive subjects. Biomedical Research. 2013;24(4):493-7.

8. Karafakioglu YS, Dundar Y, Aslan R, Fidan FA, Cigerci HI. The effects of tobacco harvesting on oxidant-antioxidant status, some biochemical and haematologic markers in women workers. Research Journal of Biological Sciences. 2009;4(6):691-6.

9. Lopes PA, Santos MC, Vicente L, Rrodrigues MO, Pavao ML, Neve J, et al. Trace element status ( $\mathrm{Se}, \mathrm{Cu}, \mathrm{Zn}$ ) in healthy portugues subjects of Lisbon population. Biological Trace Element Research. 2004;1(101):1-17.

10. Kocyigit A, Erel O, Gur S. Effects of tobacco smoking on plasma selenium, zinc, copper and iron concentrations and related antioxidative enzyme activities. Biochemistry. 2001;34(38):629-33.

11. Nakamura K, Barzi F, Valery L, Ueshima H, Woo J, Ohkubo T, et al. Cigarette smoking, systolic blood pressure and cardiovascular diseases in the Asia-Pacific Region. Stroke. 2008;39(6):1694-702.

12. Prasad AS. Clinical, immunological, anti-inflammatory and antioxidant roles of zinc. Experimental Gerontology. 2008;43(5):370-7.

13. Green MS, Jucha E, LuzY. Blood pressure in smokers and non-smokers: Epidemiologic findings. American Heart Journal. 1986;111(5):932-40

14. Butrimovitz GP, Purdy WC. The determination of zinc in blood plasma by atomic absorption spectrometry. Analysis of Serum and Plasma: Copper and Zinc. 1977;4:160-1.

15. Chhabra N, Kukreja S, Chhabra S, Kumar AN, Kumar R. Zinc deficiency a cause or a consequence of oxidative stress. Journal of Medical Science and Technology. 2012;1(2):17-24

16. Khalid S, Al-Numair. The influence of cigarette smoking on Vitamin C, trace elements and lipid profile of healthy, Saudi adult males. Journal of Food, Agriculture and Environmental. 2006;4(3 and 4):79-83.

17. Anetor JI, Ajose F, Anetor GO, lyanda AA, Babaloa OO, Adeniyi FAA. High cadmium/zinc ratio in cigarette smokers: Potential implication as biomarker of risk of prostate cancer. Nigerian Journal of Physiological Sciences. 2008;23(1-2): 41-9.

18. Azzawy LHA, Qaicy AGS. A study about some physiological parameters in smokers. Journal for Pure and Application Science. 2011;24(3):1-8.

19. Block G, Dietrich M, Norkus EP, Morrow JD, Hudes M, Caan B, et al. Factors associated with oxidative stress in human populations. American Journal of Epidemiology. 2002;156(3):274-85.

20. Bloomer RJ. Decreased blood antioxidant capacity and increased lipid peroxidation in young cigarette smokers compared to nonsmokers: Impact of dietary intake. Nutrition Journal. 2007;6(1):39.

21. Waseem SMA, Hossain MM, Islam N, Ahmad Z. Comparative study of pulmonary functions and oxidative stress in smokers and non-smokers. Indian Journal Physiol Pharmacol. 2012;54(4):345-52.

22. Primatesta P, Falaschetti E, Gupta S, Marmot MG, Poulter NR. Association between Smoking and Blood Pressure. American Heart Journal. 2001;37(2):187-93.

23. Mahmud A, Feely J. Effect of smoking on arterial stiffness and pulse pressure amplication. Hypertension. 2003;41(1):183-7.

24. Bergomi M, Rovesti S, Vinceti M, Vivolo R, Caselgrandi, Vivoli G. Zinc and copper status and blood pressure. Journal of Trace Elements in Medicine and Biology. 1997;11(3):166-9. 